\title{
Ensayo fenomenológico experiencial de enseñanza colaborativa en antropología de las copporalidades*
}

\author{
Susana Rostagnol \\ Universidad de la República, Montevideo, Uruguay \\ susana.rostagnol@gmail.com \\ https://orcid.org/0000-00017022-8869 \\ Emilia Calisto \\ Universidad de la República, Montevideo, Uruguay \\ ma.emilia.calisto@gmail.com \\ https://orcid.org/0000-0003-1044-8936
}

\section{RESUMEN}

Se reseñan los hallazgos registrados durante el curso de grado Antropología del Cuerpo de la Universidad de la República (Uruguay), en el que se propusieron algunas consignas performáticas al grupo de estudiantes. El objetivo fue introducir en el currículo actividades que pusieran en juego su experiencia directa, específicamente en los módulos relativos a la fenomenología cultural, el embodiment y el trabajo de campo como actividad encarnada. Uno de los ejes transversales del curso fue la mirada relativista sobre la construcción del cuerpo en Occidente. Por lo tanto, se pensaron actividades que, en diverso grado, pudiesen posicionar al grupo en un lugar de cierta "incomodidad" metodológica. Para diseñar las consignas se echó mano a observaciones y resultados de una investigación etnográfica en una escuela de danza contemporánea (especialmente algunas técnicas observadas en las instancias de investigación y creación). Las principales conclusiones a las que se ha arribado hasta el momento son: las hibridaciones entre antropología y danza adaptadas de manera didáctica en consignas experienciales son útiles para ampliar el saber antropológico, para preparar mejor a futuros antropólogos para el trabajo de campo y propiciar intercambios más democráticos en el aula.

Palabras clave: antropología de las corporalidades; enseñanza; consignas performáticas; pedagogía fenoménico corporal; danza.

Cómo citar: Rostagnol, S. y Calisto, E. (2020). Ensayo fenomenológico experiencial de enseñanza colaborativa en antropología de las corporalidades. Ciencias Sociales y Educación, 9(17), 57-81. https://doi.org/10.22395/ csye.v9n17a3 Recibido: 29 de noviembre de 2019.

Aprobado: 18 de febrero de 2020. 


\section{Phenomenological-Experience Exercise of Collaborative Teaching in Anthropology of Corporealities}

\section{ABSTRACT}

This paper highlights the findings registered during the grade course Anthropology of the Body of Universidad de la República (Uruguay) in which some performative premises were proposed to the students. The goal was introducing activities that involved their direct experience in the curriculum, specifically within the modules related to cultural phenomenology, embodiment, and fieldwork as an incarnated activity. One of the transversal axes within the course was the relativist vision on the construction of the body in western culture. For this reason, some activities were thought for, in a diverse grade, positioning the group in a certain methodological "uncomfortableness". For the design of these premises, the project was aided by observations and results from ethnographic research in a contemporary dance school (especially some techniques observed in the research and creation instances). The main conclusion of this work is that hybridizations between dance and anthropology adapted in a didactic manner in experiential premises are useful for widening the anthropological knowledge for better preparing anthropologist for fieldwork and for propitiating more democratic exchanges within the classroom.

Keywords: anthropology of the body; teaching; performative premises; phenomenal-corporeal didactics; dance.

\section{Ensaio fenomenológico experiencial de ensino colaborativo em antropologia das corporeidades}

\section{RESUMO}

São resenhados os achados registrados durante a graduação em Antropologia da Universidad de la República (Uruguai), nos quais são propostas diretrizes performáticas para o grupo de estudantes. O objetivo foi introduzir, no currículo, atividades que colocassem em jogo sua experiência direta, em específico nos módulos relativos à fenomenologia cultural, ao embodiment e ao trabalho de campo como atividade encarnada. Um dos eixos transversais do curso foi a visão relativista sobre a construção do corpo no Ocidente. Portanto, são pensadas atividades que, em diversos graus, possam posicionar o grupo em um lugar de certo "desconforto" metodológico. Para elaborar as diretrizes, foram utilizados observações e resultados de uma pesquisa etnográfica em uma escola de dança contemporânea (especialmente algumas técnicas observadas em contextos de pesquisa e criação). As principais conclusões a que se chegou até o momento são: as hibridações entre antropologia e dança adaptadas de maneira didática em diretrizes experienciais são úteis para ampliar o saber antropológico, para preparar melhor futuros antropólogos para o trabalho de campo e propiciar intercâmbios mais democráticos na sala de aula.

Palavras-chave: antropologia das corporeidades; ensino; diretrizes performáticas; pedagogia fenomênico-corporal; dança. 


\section{Introducción}

El presente artículo reseña los hallazgos registrados durante el curso de grado Antropología del Cuerpo, dictado en la Universidad de la República (Uruguay) en el que se propusieron algunas consignas performáticas al grupo de estudiantes. La propuesta tuvo un doble origen: nuestras inquietudes sobre la búsqueda de formas alternativas en la formación de antropólogos y antropólogas ${ }^{1} 1$, y las observaciones y resultados de un trabajo de campo etnográfico en una escuela de danza contemporánea. El objetivo que nos planteamos fue introducir en el currículo del curso actividades que pusieran en juego la experiencia directa de los estudiantes y las estudiantes, específicamente en los módulos relativos a la fenomenología cultural, el embodiment y el trabajo de campo antropológico como actividad encarnada ${ }^{2}$. Dado que el curso se desarrolló en el primer semestre del año 2019, aún nos encontramos en proceso de evaluación y valoración de la experiencia. Sin embargo, se pueden adelantar ciertos hallazgos preliminares. En particular, interesa destacar que, al dislocar la metodología de trabajo tradicional del aula universitaria, surgen saberes que estudiantes y docentes reconocemos como conocimiento original. Asimismo, estos saberes configuran nuevas posibilidades otras de comprensión de la práctica y el conocimiento antropológicos.

Como es de imaginar, uno de los ejes transversales del curso era establecer una mirada que desde la antropología cuestionase la construcción del cuerpo en Occidente. Por lo tanto, se pensaron actividades que, en diverso grado, pudiesen posicionar al grupo de estudiantes a lo largo del semestre en un lugar de cierta "incomodidad" metodológica. Para esto se entendió que era útil plantear actividades más allá de la estricta lectura de textos: visualizar videos con prácticas que nos cuesta imaginar si nunca las presenciamos de primera mano, como una cura chamánica; dibujar la autoimagen corporal, casi imposible de visualizar y describir si no se intenta un esbozo gráfico de la misma; vivenciar sensaciones como el movimiento entre objetos que son obstáculos para el desplazamiento o el contacto corporal con algún compañero, entre otras.

Al diseñar el curso, también nos interesaba llevar a la práctica y poner a prueba el diálogo existente entre dos áreas disciplinares: por una parte, las artes escénicas (sean danza o teatro), la performance arte y la expresión corporal; por otra parte, la antropología y los estudios de la performance y los cuerpos. Ha sido ya registrado en diferentes publicaciones y recopilaciones que existe una genealogía disciplinar que podríamos llamar teórico-corporal dado que quienes se han dedicado a la antropología del cuerpo o de la danza

De aquí en adelante se acogerá el uso del lenguaje inclusivo en el siguiente aspecto: el desdoblamiento de los artículos y los sustantivos en femenino y masculino.

2 Específicamente la segunda y la tercera parte del curso: "Los cuerpos en acción, corporeidades" y "El cuerpo en la producción de conocimiento antropológico", respectivamente. 
también se han abocado a bailar o practicar otras disciplinas corporales desde su costado artístico, terapéutico o ritual. Casi todas las antropólogas que han realizado aportes relevantes en la antropología de la danza han bailado de manera profesional o amateur en algún momento de sus carreras. Cynthia Novack (1992) (conocida también como Cynthia Cohen Bull) explica claramente los beneficios de estas trayectorias:

Siento que mi experiencia en danza me ha proveído de la base para las percepciones y formulaciones como antropóloga [...] me ha servido como un modelo experiencial para las potenciales esperanzas y frustraciones de la creación colectiva y la interacción social, y para las sutiles interrelaciones de la estructura, la toma de decisiones, y la posibilidad [...] me ha dado también mi trabajo de campo etnográfico y de escritura sobre la danza sensibilizándome a los fenómenos kinestésicos y coreográficos, y alertándome de las múltiples perspectivas presentes en los eventos dancísticos. (p. 83, traducción propia)

En la performance se da una hibridación similar, cuyos más relevantes representantes sean quizá Richard Schechner y André Lepecki (citados por Taylor, 2011). Al reconocer "[...] que la teoría mejora la práctica y que la práctica siempre escenifica una teoría, quiérase o no" (Taylor, 2011, p. 12), nos interesó poner a prueba ese diálogo para entender tal escenificación de manera profunda, como una performance situada. En este sentido, nuestro ejercicio debería partir de reconocer nuestra situacionalidad en el aula universitaria, en nuestros cuerpos tanto de estudiantes como de docentes, para luego volcar una mirada antropológica y dialógica sobre ellos.

El presente artículo reseña, en primer lugar, las grandes referencias teóricas que sustentaron la propuesta desde el punto de vista de la filosofía, la teoría antropológica y la teoría educativa. En segundo lugar, se reseñan las actividades realizadas que se derivaron de los hallazgos realizados en el trabajo etnográfico con la danza y las ideas teóricas, antropológicas y didácticas en las que se referencian.

\section{La tematización}

Dado que nuestra intención era probar algunos resultados de una investigación en el campo de la enseñanza de la danza (especialmente técnicas observadas en las instancias de investigación dancística) y en el campo de la enseñanza de la antropología, no nos referiremos exactamente a un problema de investigación, sino que, inspirándonos en las propuestas de Paulo Freire (1973), nos referiremos a una tematización. Este concepto refiere a la delimitación conceptual como un acto de enunciación político y educativo efectuado en una relación humana. La tematización freireana podría plantearse como lo opuesto a la reificación. Los temas surgen en la experiencia educativa entendida 
como una praxis, de modo que es imposible disociar tanto a la teoría de la práctica, como a los sujetos de su situacionalidad.

En nuestras clases de antropología repetimos una y otra vez que el trabajo de campo es ante todo una experiencia que resulta en la producción de conocimiento. Este proceso se nutre tanto de destrezas cognitivas y racionales, como de vivencias corporales, emociones y afectividad. Resulta, por tanto, incongruente que en las clases de antropología, a quienes nos toca el rol docente, tratemos a estudiantes como tabulas rasas (Lorenc, 2014) o, en palabras de un estudiante, como "escritorios pensantes". Dejando de lado los centros de estudios de artes escénicas o deportivos, la universidad tiene un habitus de enseñanza más bien logocéntrico, donde cuerpo, emociones y afectividad no tienen espacio. Aunque esto nos resultaba molesto, no contábamos con herramientas para poner en práctica formas alternativas. No se trata de que un estudiante acumule conocimientos de manera bancaria (Freire, 1973), sino que cuente con elementos que le permitan comprender la realidad circundante al tiempo que desarrolle su creatividad para poder plantear nuevos interrogantes. Ya Evans Pritchard había señalado que la capacidad intelectual y la preparación técnica no eran suficientes para la formación de un buen antropólogo (citado en Peirano, 1995, p. 124). Son varios los ejemplos provenientes de la antropología que muestran cómo una persona desarrolla una habilidad por fuera de estructuras de instrucción directa y simplemente por encontrarse inmersa en una comunidad de práctica. La investigación en una escuela de danza contemporánea nos permitió observar diversidad de aprendizajes que no siempre son iniciados o mediados por la razón analítica, sino que se producen en una experiencia no lingüística. Esta luego podrá ser verbalizada o tramitada por otros canales cognitivos según las necesidades educativas del momento, por ejemplo, al poner nombres a partes de las frases de una coreografía u ordenar el material de la improvisación para una puesta en escena.

\section{Nuestra propuesta híbrida}

\section{Los componentes pedagógico-didácticos}

En primer lugar, retomamos la idea de un pensamiento complejo que produce conocimientos situados. Recordemos que la propuesta de Morin (2009) con respecto al pensamiento es antiesencialista,

[...] supone y explicita una Ontología, que no solamente pone el acento sobre la relación en detrimento de la sustancia, sino que también pone el acento sobre las emergencias, las interferencias, como fenómenos constitutivos del objeto. No hay más que una red formal de relaciones, hay realidades, pero que no son esencias, que no son de una sola sustancia, que son compuestas, producidas por los juegos sistémicos, pero dotadas, de todos modos, de una cierta autonomía. (p. 46) 
En esta red de relaciones se sitúa el conocimiento, que no es neutral ni científicamente aséptico, ni puede ser considerado objetivo fuera de las relaciones sociales que lo engendran y lo construyen. Para Donna Haraway (1985), epistemóloga proponente por excelencia de la idea del conocimiento situado, lo que sucede es que

[...] nuestra insistencia metafórica en la particularidad y en la encarnación de toda la visión (no necesariamente una encarnación orgánica que incluya una mediación tecnológica) y nuestro no ceder ante los mitos tentadores de la visión como un camino hacia la des-encarnación y un nacer de nuevo, nos permiten construir una doctrina de la objetividad utilizable, pero no inocente. (p. 326)

Por otra parte, con respecto al origen material del conocimiento humano, construido desde situacionalidades en contextos socioculturales específicos y en cuerpos concretos y encarnados, podemos referirnos a los trabajos de algunos autores vinculados a las neurociencias. Si bien las múltiples aplicaciones de estas ideas están en debate y son discutibles, algunos de sus postulados abrevan por la diversificación de la matriz del conocimiento y por descentrar el eje logocéntrico Occidental. Estas plantean que el sistema nervioso central y el cerebro (de la mano con sus capacidades lingüísticas y matemáticas) han desmerecido el potencial de los aprendizajes que ocurren o son estimulados desde otros puntos del sistema nervioso. En este sentido, entendemos que es interesante recuperar algunas afirmaciones al respecto hechas por Lakoff y Johnson (1999):

- Un concepto encarnado (embodied) es una estructura neuronal que es de hecho parte, o hace uso, del sistema sensoriomotor de nuestro cerebro (our brains). Mucha de la inferencia conceptual, es entonces, inferencia sensoriomotora. (p. 20, cursivas del original)

- Es el nivel más elevado en el que una persona usa acciones motoras similares para interactuar con miembros de la misma categoría. Usted tiene programas motores para interactuar con objetos en el nivel básico, para interactuar con sillas, mesas y camas. Pero, usted no tiene programas motores para interactuar con objetos muebles generalizables. (p. 28)

- En suma, nuestras categorías emergen del hecho de que somos seres neuronales, de la naturaleza de nuestras capacidades corporales, de nuestra experiencia interactuando en el mundo, y de nuestra evolucionada capacidad para categorizar en el nivel básico- un nivel en el que interactuamos de forma óptima con el mundo [...] Los hechos del nivel básico de categorización también nos recuerdan que nuestros cuerpos contribuyen a nuestro sentido de qué es lo real. (p. 30, traducción propia)

En el ámbito de lo educativo, una de las influencias fundamentales databa de la década de los ochenta, cuando cobró relevancia el concepto de inteligencias múltiples que estableció que, más allá de qué concepto aprender, 
existen diferentes modalidades de acceder a él. Estas modalidades, estilos, o inteligencias (según el enfoque teórico) van desde el pensamiento lógico formal hasta lo kinestésico, pasando por lo espacial y musical, entre muchas otras. Las inteligencias son mucho más que las habilidades lingüísticas y lógico matemáticas (Gardner, 1983).

Décadas antes, las propuestas filosóficas y educativas provenientes de las ciencias sociales como la "escuela activa" de Dewey (1938) mostraron que los aprendizajes fuertemente enraizados en la experiencia son efectivos y son los que más se asemejan a las dinámicas propias de las sociedades humanas. En este sentido, Dewey (1938) también alertaba del riesgo de estrechar demasiado las experiencias educativas, ya que una "experiencia dada puede incrementar la habilidad automática de una persona en una cierta dirección, pero incluso, tender a arraigar a esa persona en unos hábitos o rutinas; nuevamente el efecto es disminuir el campo de las experiencias futuras" (pp. 25-26). Así, la planificación consciente y directa de experiencias educativas es fundamental para ampliar el rango de experiencias a las que los sujetos podrán estar receptivos y disponibles en futuras situaciones. Más aún, esta posibilidad se vuelve crucial al referirnos a un trabajo de campo como el etnográfico en el que debemos desplegar todos nuestros sentidos en el campo para leer, interpretar o dialogar con la otredad de la manera más rigurosa y profunda posible.

Si nosotras pretendíamos formar antropólogos y antropólogas que en sus investigaciones pudieran echar mano a todas sus habilidades, en el entendido que el conocimiento sucede en el antropólogo (Peirano, 1995), entonces teníamos que buscar la manera por la cual el proceso de formación también considerase sujetos integrales. Incorporamos, entonces, la noción de "aprendizaje kinésico" (Jackson, 2010) y nos inspiramos en algunos principios del embodied learning (Panagiotis et al., 2018; Paniagua e Istance, 2018), aun cuando se trata de un abordaje originalmente pensado para el trabajo con niñas y niños. Cabe retomar algunos de sus postulados, a saber:

- Cuerpo y mente trabajan juntos en el aprendizaje.

- Los movimientos y los conceptos están conectados.

- La acción y el pensamiento son simultáneos.

- La ciencia y el arte se influyen y apoyan recíprocamente.

- Lo físico y lo ideacional discuten entre sí.

- La realidad y la imaginación están entretejidas.

- El cuerpo viviente y el cuerpo vivido se unen al formar la conciencia humana.

(Svendler et al., 2012) 
Tal como lo explican Nguyen y Larson (citados en Panagiotis et al., 2018) en los contextos de embodied learning los aprendientes son "simultáneamente cuerpos sensorimotores, mentes reflexivas y seres sociales" (p. 594). Desde esta perspectiva, el embodiment conecta con la experiencia vivida, ya que es el resultado del compromiso sensorial con el ambiente, mientras que la cognición se sitúa en una retroalimentación constante entre la persona y el ambiente (Paniagua e Istance, 2018, p. 118). Así, las experiencias, emociones y sensaciones pasan a desempeñar un papel central en el proceso de aprendizaje. Y son estas las que se conectan con los aspectos estrictamente mentales, a fin de llevar adelante procesos más comprehensivos, lo que demuestra, al mismo tiempo, que no todo conocimiento es intelectual.

A diferencia de la perspectiva cartesiana que trata los afectos en su doble dimensión psicofísica, la Educación Corporal pretende poner los afectos (affectus) como atributos de poder de la corporalidad; así las emociones, motivaciones, sentimientos, la imaginación o, por ejemplo, el miedo, el temblor, la risa, el llanto, son afecciones que se refieren a toda la corporalidad. Una afección como la imaginación en el aula puede aumentar o disminuir la potencia de obrar del cuerpo, favorecerla o reprimirla. En términos pedagógicos, la imaginación puede generar afección si tiene un impacto sobre la potencia de obrar del cuerpo, es decir, si la imaginación genera potencia de pensar, crear y experimentar o en tanto produce efectos particulares. (Gallo y Martínez, 2015, p. 618)

Finalmente, desde el gran paradigma del aprendizaje colaborativo buscamos incorporar todas estas dimensiones del o de la aprendiente para integrar las múltiples inteligencias que puedan convivir en él o ella, sin dejar de considerar la afectividad. Así, se intentan dislocar las restricciones de la lógica individualista de la persona occidental de matriz (kantiana). Para ello también tomamos insumos de la teoría del aprendizaje situado en comunidades de práctica, desarrollado por Lave y Wenger (1991) y profundizado por Lave (1991). La idea que desarrollan estos autores, al recuperar el papel del aprendiz de un oficio -aunque no sea del todo instrumentalizable en una clase universitaria de antropología-, nos resultó atractiva puesto que plantea llevar la comunidad de práctica al aula. En este sentido, intentamos nutrirnos de algunas de sus propuestas, especialmente del valor que dan a lo social en el hacer con otros. Dentro de este hacer con otros retomamos las ideas de Haraway (1985) de que todo conocimiento es situado, y de Freire (1973) de que todo acto educativo debería ser una praxis política de libertad. Así, los saberes que circularon en el aula de Antropología del Cuerpo se nutrieron de toda la rica historia disciplinar proveniente tanto del norte como del sur, pero siempre en diálogo con nuestra realidad local y las inquietudes que surgieron de un grupo integrado por estudiantes de diversas edades, orígenes socioeconómicos e historias personales que los llevaron a encontrarse en una clase de una universidad abierta y gratuita de un pequeño país del sur del sur. 


\section{La antropología de y desde las corporalidades. Saberes por construir y deconstruir}

Como fue tempranamente planteado por Mauss (1979) con el hombre total biológico, social y psicológico, algunos fenómenos humanos son indisociablemente subjetivos y grupales al mismo tiempo, a pesar de que muchas veces son preobjetivos, como las diferentes técnicas corporales existentes para caminar. En nuestro contexto contemporáneo ha quedado claro que el cuerpo humano puede ser entendido y abordado epistemológicamente como un cuerpo cognoscente. Dentro de la línea fenomenológica, Csordas (2010) plantea que el compromiso sensorial es pautado culturalmente y, por tanto, aprendido (lato sensu) y plausible de ser estudiado como fenómeno antropológico.

En cuanto a la metodología de investigación de estos fenómenos, Wacquant (2015) ha demostrado con su propuesta de una sociología carnal que siempre -pero más aún para acercarse y comprender fenómenos claramente corporales (como el boxeo) -, es necesario participar de los mismos e incluir en el análisis la experiencia corporizada de quien investiga.

[...] como una criatura sensible, sufriente, hábil, sedimentada, y corpórea. Subrayo la primacía del conocimiento práctico encarnado que emerge de y está continuamente imbricado en redes de acción, sobre el que la competencia lingüística es inserta. Considero entonces qué modos de indagación encajan para desmenuzar y explotar esta concepción encarnada del animal humano. Sugiero que la etnografía enactiva, la línea de trabajo de campo de inmersión que se basa en "performar el fenómeno" es un camino fructífero hacia la comprensión de los esquemas cognitivos, conativos y catéticos (es decir, el habitus) que generan las prácticas que subyacen a nuestro cosmos de investigación. (p. 2, traducción propia)

Este tipo de abordaje, que también se ha dado en llamar participación observante, nos obliga, según Sabrina Mora (2012), a considerar un conocimiento corporizado que incluya y trascienda la antropología reflexiva, porque nos permite volcar nuestra atención hacia las sensaciones y vivencias que habitan nuestros propios cuerpos de investigadores e investigadoras, a cuestionarnos sobre las reacciones e interacciones somáticas de nuestro estar-en-el campo con la presencia de otros y otras.

\section{Las prácticas por hibridar}

Como ha sido largamente trabajado por disciplinas como la expresión corporal o algunas corrientes de la danza y el teatro, hay un cierto conocimiento que solo es accesible si se aplaza, retrasa o minimiza lo verbal, lo espectacular, lo mimético, y se atraviesan determinadas experiencias. En sí misma, como lo dicen Stokoe y Harf (1984), “[l]a expresión corporal es una conducta espontánea existente desde siempre, tanto en sentido ontogenético como filogenético; [...] expresa sensaciones, emociones, sentimientos y pensamientos con [el] 
cuerpo" (citado en Sánchez, 2009, p. 27). Habitualmente, este tipo de conocimiento que podríamos llamar corpoexperiencial es patrimonio de técnicas, disciplinas o saberes cuyos ejes pasan por la anatomía corporal, el movimiento, el bienestar, la relación con lo afectivo, entre otras. Y en general es desdeñado por las instituciones académicas, superiores y científicas. Pero la antropología contemporánea nos demuestra que conocer desde la experiencia sensorial, corporal y que es propia de un saber preobjetivo y prediscursivo, es parte de la vida humana: de los procesos de acumulación cultural, de enseñanzaaprendizaje, de conocimiento e investigación de los fenómenos humanos. Como ejemplifica desde la filosofía de la danza Marie Bardet (2012):

Si esta idea de que la improvisación surge de ninguna parte es un mito persistente, el mito de la página en blanco, es porque cuenta bien la problemática intrínseca: una inmediatez que sin embargo no surge de ninguna parte, se despliega en un lugar, en una serie (...) y hace del presente un proceso de continuidad y diferenciación, al mismo tiempo que hace de la presencia una atención a la realidad en curso. (p. 133)

Incluso en los procesos de improvisación dancística, no existen ni la tabula rasa ni la página en blanco. Creación, cognición y percepción son históricas, ocurren en el presente, se oponen al pasado y se proyectan hacia el futuro; colapsa la sincronicidad y la diacronicidad en la carne misma de los cuerpos.

\section{Línea de fuga entre antropología, cuerpos y danzas}

Buscamos hibridar modos de hacer, enseñar e investigar; incluir lo corporal en nuestra propuesta dado que:

La educación corporal posibilita el acercamiento a las fuerzas que componen el cuerpo, aquellas que se desplazan entre líneas y que producen ciertos modos de ser y habitar el mundo, ciertas subjetividades; (y) se trata de estar atento a las líneas, a los encuentros, a las fuerzas y al movimiento que se desprende, a las conexiones que se establecen con el mundo para permitir la creación de pensamientos diferentes que afecten los modos de existir. (Gallo y Martínez, 2015, p. 626)

En nuestra propuesta del curso, fue especialmente importante exponer a los estudiantes a diversas experiencias que les permitieran cuestionar el pensamiento eurologocéntrico, en particular con referencia al cuerpo, que les permitiera trascender las nociones hegemónicas de raíz cartesiana e impregnadas por las visiones biomédicas como dualismos únicos y totalizantes. Al retomar la anécdota relatada por Jackson (2010) con respecto a la especial forma de encender el fuego entre los Kuranko, concluimos que sería útil generar propuestas híbridas que aprovechen los aprendizajes resultantes del trabajo de campo en la escuela de danza contemporánea, con el fin de desarrollar un abordaje pedagógico, corporal y situado para nuestras clases de antropología. 
Por lo tanto, nos fijamos como objetivo diseñar algunas experiencias que partieran de las grandes propuestas del curso Antropología del Cuerpo y ofrecieran al grupo instancias en las que se pudiera maximizar un saber visto desde la perspectiva clásica, conceptual, expositiva; o que los hicieran atravesar experiencias sensoriales a partir de las cuales los estudiantes y las estudiantes pudieran registrar nuevas maneras de estar en el campo o de percibir el saber antropológico. Para esta tematización pusimos en diálogo abordajes somáticos de la investigación artística en danza, como el Contact Improvisación (CI) y la sensopercepción (Sánchez, 2009) con la fenomenología cultural (Merleau-Ponty, 1993; Csordas, 1998).

Finalmente, con el cuerpo como un inasible, construido cultural y disciplinariamente de diferentes maneras, nos embarcamos en un proceso de deconstrucción a través de herramientas conceptuales de la antropología clásica y contemporánea, y de experiencias que, vividas en tiempo presente, habilitasen nuevos conocimientos. En el siguiente apartado se repasarán tres de esas experiencias, sus relatos, impactos y aprendizajes.

\section{La narración de las experiencias}

El curso Antropología del Cuerpo forma parte del menú de optativas para completar los créditos del módulo general de la carrera ${ }^{3}$. El curso se aprueba mediante la realización correcta de dos parciales domiciliarios y lecturas continuas durante todo el proceso. En esta edición participaron aproximadamente cuarenta estudiantes y lo concluyeron treinta y dos. El dictado del curso se dividió en dos clases semanales de dos horas cada una. Una de ellas se dictaba en un antiguo salón de actos y la otra en un moderno salón. En el primer caso las sillas estaban fijas, en el segundo caso nos ubicamos en un gran círculo de modo que todos y todas podíamos vernos, establecer contacto visual y, en principio, intercambiar ideas cara a cara. Pero más allá de los ricos intercambios discursivos y conceptuales en torno a las lecturas hechas, ensayamos otro tipo de experiencias didácticas. A continuación, repasaremos algunas de ellas y los aprendizajes que nos dejaron.

\section{Poniendo el cueppo en un antiguo salón de actos}

Los primeros capítulos de la Fenomenología de la percepción de Merleau-Ponty (1993) fueron leídos por el grupo a modo de tarea domiciliaria. Al llegar a la clase se hizo una breve introducción y se realizó una primera puesta en común de lo leído. Un número de estudiantes manifestaron las dificultades que el texto les presentó

La licenciatura tiene un módulo general para todos los estudiantes y las estudiantes, y módulos específicos, tales como Antropología Social, Arqueología o Antropología Biológica. Cada módulo tiene aproximadamente la mitad de los créditos. 
por su tipo de escritura y cómo les había costado sintetizar las conceptualizaciones leídas. De alguna manera, esto no representó una sorpresa para nosotras, ya que para quien se haya acercado a la obra de Merleau-Ponty es ineludible ponerla en relación con la experiencia pasada o presente para maximizar la comprensión del texto en cuestión. Si bien habrá quienes entiendan los conceptos expuestos por el filósofo con la sola lectura, asumimos que el texto plantea un diálogo con la realidad y con el estar-en-el-mundo de la obra misma y de quién la lee. Tanto es así que algunos pasajes parecen invitarnos -o inclusive incitarnos-a cuestionar lo que vemos, lo que sentimos y cómo lo hacemos.

Por tanto, luego de ese primer intercambio de la lectura domiciliaria, en el que efectivamente se plantearon más dudas que certezas, habíamos planificado dos actividades. La primera, que llamamos de percepción somática, se inspiró en consignas habitualmente propuestas en clases de danza contemporánea o expresión corporal a modo de caldeamiento ${ }^{4}$. En esta actividad, a través de una guía, quien vivía la experiencia iba dirigiendo su atención a su estar-enel-mundo, a habitar un momento sin desplazarse o con algunos movimientos realizados solo en función de una búsqueda de comodidad para habitar el espacio que ocupaba su cuerpo físico. El objetivo de esta actividad era activar la percepción en general, y llevar el foco de la atención a la kinestesia.

La guía era dada de forma oral, leyendo de manera suave y continua el siguiente guion:

Les vamos a pedir que por unos minutos se queden en la silla quietos, o al menos pasivos, probablemente se le vengan a la mente las actividades del día, o lo que hicieron antes, etc., pero, intenten ir dejando atrás esas ideas y tratar de habitar su presencia, contaremos 5 minutos. (Registro de una experiencia de taller, 24 de abril de 2019)

Una vez pasados los cinco minutos en silencio, se plantea lo siguiente, también de forma suave y continua.

Ahora les pedimos que enfoquen su atención en:

- Si hicieron movimientos en la silla, ¿cuáles fueron y por qué? ¿estaba incómoda, presionaba alguna parte del cuerpo?

- ¿Tosieron/estornudaron/sintieron escozor? ¿cómo fue la sensación de la tos? ¿cuándo fue la última vez que habían tosido/estornudado/rascado? ¿y la anterior?

- ¿Me molesta alguna prenda de ropa? ¿Me apretan las medias? ¿El calzado?

Para Patricia Stokoe (1984), creadora de los conceptos expresión corporal y sensopercepción, esta última se debe utilizar o activar en una primera etapa del proceso de trabajo, ya que se trata de "una técnica de base para el conocimiento del propio cuerpo, de su afinamiento, concentración y escucha" (citado en Sánchez, 2009, p. 27). 
- ¿Les dio frío o calor? ¿algún punto del cuerpo está más caliente o frío que el resto? ¿que genera esa sensación? es agradable/desagradable? en qué otros momentos la han sentido o sienten habitualmente?

- ¿Les dolió algo? ¿cuánto hace que duele? ¿cuándo fue la última vez que les dolió? se golpearon allí? tienen una contractura?

- ¿Les dio sueño? bostezaron? cuándo fue la última vez que se durmieron? o despertaron? qué acompaña al bostezo? lágrimas? otro bostezo? cuántas veces al día bostezo? o cambio o noto mi respiración?

- ¿Cómo es mi respiración? la puedo percibir? ¿Qué pasa cuando pienso en mi respiración? ¿Me hace acordar a algún momento especial? de nerviosidad/ tensión?

- ¿Les dio hambre? ¿Cómo saciaría mi hambre en este momento? ¿o que comerían? ¿cuándo fue la última vez que comieron? ¿o la última vez que tuve hambre?

- ¿Se les durmió alguna parte del cuerpo? que sensación genera? ¿en qué otros momentos se me duermen partes del cuerpo? ¿cuándo fue la primera vez en mi vida que sentí esa sensación de "dormido"?

- ¿qué pasa en la boca? ¿con la saliva? ¿con los ojos? ¿se humedecen? ¿se secan? ¿da sed?

- ¿Les dieron ganas de ir al baño? ¿Qué sensación es esa? ¿cuándo fue la última vez en el día que fueron al baño? ¿y la anterior? ¿y la anterior? ¿vienen fácilmente esos recuerdos?

Les pedimos que tomen lápiz y papel y escriban las "respuestas", pueden elegir varias o tomar una profundizar, ver si siguen sintiendo lo mismo, hasta dónde la pueden historizar. la idea es que escriban durante 5 minutos más esas vivencias o sentires corporales a medida que aparezcan, sin pensarlos demasiado. (Registro de una experiencia de taller, 24 de abril de 2019)

Luego de esta activación sensorial, se planteó al grupo una actividad enfocada hacia la propiocepción y exteropercepción. A medida que se iban llevando adelante las consignas, se iban leyendo, a través de un micrófono, pasajes de la Fenomenología de la percepción que se vinculaban y se podían resignificar en la experiencia que se estaba viviendo. La actividad se dividió en tres fases. En la primera se pidió al grupo que cada persona eligiera un lugar del salón, se parara y se dirigiera hasta allí. Al llegar, debía escribir qué movimientos tuvo que hacer para efectuar ese recorrido y qué objetos tuvo que reconocer o esquivar. Se trataba de un salón, a primera vista muy incómodo para una actividad de este tipo, ya que es un antiguo auditorio con butacas fijas, estrechos pasillos y desniveles.

El bastón del ciego ha dejado de ser un objeto para él, ya no se percibe por sí mismo, su extremidad se ha transformado en zona sensible, aumenta la amplitud y el radio de acción del tacto, se ha convertido en lo análogo de una mirada. En la 
exploración de los objetos, la longitud del bastón no interviene de modo expreso y como término medio: el ciego la conoce gracias a la posición de los objetos, más que la posición de los objetos gracias a ella. La posición de los objetos viene inmediatamente dada por la amplitud del gesto que la afecta y en la que están comprendidos, además del poder de extensión del brazo, el radio de acción del bastón. Si quiero habituarme a un bastón, lo pruebo, toco algunos objetos y, al cabo de un tiempo, lo tengo "por la mano", veo qué objetos están al alcance de mi bastón o fuera de su alcance. No se trata aquí de una comparación entre la longitud objetiva del bastón y la distancia objetiva del fin por lograr. Los lugares del espacio no se definen como posiciones objetivas respecto de la posición objetiva de nuestro cuerpo, sino que inscriben alrededor de nosotros. (Merleau-Ponty, 1993, p. 160, cursivas nuestras)

En segundo lugar, se pidió a los participantes y a las participantes que se sentaran en el lugar elegido y observaran hacia una dirección, que dirigieran su mirada conscientemente hacia allí y observaran el paisaje. Luego se les pidió que trataran de memorizar una descripción real y al mismo tiempo imaginada de este: ¿qué hay más allá de la puerta del salón? ¿lo vemos? ¿lo sabemos/ conocemos? ¿lo imaginamos?

Nuestro campo visual no está recortado en nuestro mundo objetivo, no es un fragmento del mismo con unos bordes claros como el paisaje que se encuadra en la ventana. Vemos tan lejos como se extiende la presa de nuestra mirada en las cosas -mucho más lejos de la visión clara e incluso detrás nuestro. Al llegar a los límites del campo visual no pasamos de la visión a la no-visión: el fonógrafo que toca en la habitación contigua y que no veo expresamente, cuenta aún en mi campo visual; recíprocamente, lo que vemos siempre es, en ciertos aspectos, no visto: es necesario que haya lados ocultos de las cosas y cosas "detrás nuestro", si tiene que haber un "delante» de las cosas, cosas "delante de nosotros" y, por fin, una percepción. Los límites del campo visual son un momento necesario de la organización del mundo, y no un contorno objetivo. (Merleau-Ponty, 1993, p. 292)

Por último, se pidió a cada persona que buscara un compañero o una compañera y le invitara a hacer el mismo recorrido; que lo guiaran como quisieran, pero conservando sus cuerpos a corta distancia, a una distancia que, desde su propia perspectiva proxémica, estuviera en el límite de la cercanía social/personal. Luego, al llegar al lugar, debían mostrarles su paisaje y relatarles su descripción. Finalmente, nos preguntamos: ¿Qué cambió en el recorrido con el otro? ¿Qué le llamó la atención al compañero o compañera de mi relato del paisaje?

La adquisición de la habilidad es la captación de una significación, pero la captación motriz de una significación motriz. ¿Qué quiere decir eso, exactamente? Una mujer mantiene sin cálculo un intervalo de seguridad entre la pluma de su sombrero y los objetos que podrían troncharla, siente donde está la pluma como nosotros sentimos donde tenemos la mano. Si tengo el hábito de conducir un coche, lo meto por un camino y veo que "puedo pasar» sin tener que comparar la anchura del mismo con la de las alas del coche, como atravieso por una puerta sin comparar la anchura de la misma con mi cuerpo.108 El sombrero y el automóvil han dejado de ser objetos 
cuyo volumen y tamaño se determinaría por comparación con los demás objetos. Se han convertido en potencias voluminosas, la exigencia de un cierto espacio libre. (Merleau-Ponty, 1993, p. 160)

Luego de esta experiencia, el grupo cambió su estar-en-el-salón. La gran mayoría se quedó sentada en otros lugares diferentes a los habituales, se agrupó de manera espontánea e intercambiaron ideas de manera entusiasta sobre la experiencia, los capítulos de la Fenomenología de la percepción trabajados y sobre otros temas de interés compartidos que escapan a la dupla docente, autoras de este escrito. Todo esto representó una dislocación del habitual estar en el salón de clase y, por tanto, una posibilidad distinta de recepción. Inmediatamente después, se hizo una puesta en común de la experiencia. Los estudiantes y las estudiantes compartieron una cantidad de reflexiones sobre las ideas de Merleau-Ponty, pudieron conectar ideas de la Fenomenología de la percepción con la experiencia previa, su vida cotidiana y sus trabajos de campo. Entendemos que a través de esta propuesta se logró nuestro objetivo de que el grupo aprehendiera algunas ideas básicas de la fenomenología. La experiencia funcionó como una

relación práctica con el mundo [que] no se da en términos de un 'yo pienso' sino de un 'yo puedo'. En aquello que 'intentamos' nuestro cuerpo apunta hacia un mundo, tratando de incorporarlo -desde movimientos sencillos como tomar un objeto o desplazarnos por el espacio hasta hábitos complejos como utilizar herramientas. (Citro, 2009, p. 47)

\section{La pequeña danza}

Susana Tambutti (2009) afirma: "Leer a Merleau-Ponty implica entrar en un estilo donde el modo de decir se confunde con lo dicho, la palabra vibra, sale de su lugar representacional para devolvernos la experiencia del cuerpo en palabra" (p. 6). Entonces, para cerrar la unidad sobre fenomenología nos interesaba dar un paso más para que el grupo pudiese atravesar una experiencia aún más profunda de lo propioceptivo, que a su vez le sirviese como activación sensorial para sus investigaciones de campo. Para ello, recurrimos a un texto del antropólogo Lepecki (2006) a quien conocimos gracias al trabajo de campo en la danza llamado Agotar la danza: performance y política del movimiento. Comenzamos a leerlo porque su obra era habitualmente citada en conversaciones con bailarinas y bailarines. Para nuestras clases decidimos trabajar el texto "Inmóvil: sobre la vibrante microscopía de la danza" (Lepecki, 2011) en combinación con una propuesta de Contact Improvisation (CI) llamada pequeña danza (Paxton, 2017). El CI fue creado por Steve Paxton y es claramente descrito como una técnica fenomenológico-experiencial por Daniel Lepkoff (2011), bailarín y teórico contemporáneo de Paxton que participó en los primeros encuentros en la 
década del 1960, en los que el CI fue creado. Lepkoff (2011) describe al CI como un proyecto que se propone:

Diseñar una forma de performance que desvíe cualquier impulso del bailarín guiado estilística o estéticamente, revelando un nivel físico de funcionamiento que es comúnmente inconsciente [...] El artificio de Steve [Paxton] fue poner el cuerpo del bailarín en situaciones inusuales, desorientadoras y, en general, emergentes. [...] En estas situaciones, uno no puede confiar en los hábitos; los reflejos se adueñan, y el resto es historia. La técnica necesaria que subyace para prepararse y sobrevivir a las sorpresas del dúo del CI es postular y mantener una pregunta [...] Este preguntar, más que ser formulado con la mente verbal de cada quien, es formulado y reside entre los tejidos del cuerpo: huesos, músculos, órganos, nervios y cerebro [...] a través de mis sentidos físicos puedo recoger información directamente de mi ambiente- usando mis propios poderes de observación puedo cambiar mi perspectiva, tener nuevas percepciones y liberarme a mí mismo de mis propias y convencionales formas de mirar. [...] mi atención necesita estar constantemente en movimiento. Reconocer lo que estoy reconociendo es la parte más sencilla; reconocer lo que no estoy percibiendo es el desafío. Cuando mi atención cesa de moverse, mi interpretación de lo que se ve se vuelve fija y mi visión se convencionaliza, es por eso que el preguntarme desaparece. La percepción sigue a la atención. El CI ha fijado mi atención en un sujeto elusivo, pero que a la vez provoca nuevas percepciones. (p. 41)

Por su parte, Lepecki (2000) pone en diálogo algunas propuestas dancísticas modernas y contemporáneas que apelaron a la inmovilidad, entre ellas $\mathrm{La}$ pequeña danza del CI, la idea de Merleau-Ponty de la filigrana de la percepción y el concepto acuñado por Suely Rolnik (2004) de cuerpo vibratorio. El texto es profundo. A través de coreografías concretas y puestas en escena, Lepecki realiza un sustantivo análisis fenomenológico de las corporalidades, partiendo de la Modernidad hasta el presente. Uno de los ejes del texto es la relación del sujeto con su inmovilidad, puesto que esta no es tal, sino una inmovilidad que habilita la percepción del cuerpo vibratorio.

[L]a inmovilidad que analizamos no abreva de las cualidades de la fijeza, sino que se trata de una categoría ontológica, un umbral sensorial, una intensidad vibratoria provocada por el rechazo del sujeto a comprometer su cuerpo en movimientos impensadamente continuos, sobredeterminados, prescritos, y en subjetividades y cuerpos-imagen. Esta inmovilidad vibratoria reconfigura la relación misma entre corporalidad y subjetividad, en tanto chocan en la formación de umbrales sensoriales en el campo de fuerza cultural-histórico que es el mundo. (Lepecki, 2011, pp. 541-542)

Esa fuerza cultural-histórica se percibe en lo sutil de una filigrana; lo invisible existe gracias y en oposición a lo visible. Con respecto a la visión que se fijaría si dejase de oponerla con preguntas en la "filigrana" intersticial de lo visible, Lepkoff (2011) afirmaba que, para el movimiento, la inmovilidad opera "como la amenaza intersticial cuya erupción inminente e incontrolable definía y contenía los límites mismos de la imaginación coreográfica" (Lepecki, 2011, p. 531). 
La actividad concreta que se propuso al grupo fue tomada de talleres de danza en los que se propuso a algunos participantes bailar con una consigna, mientras que otros observaban y tomaban notas (en los talleres de danza en general estos roles rotan y se intercambian los materiales escritos). Según lo observado, este tipo de consigna resulta muy útil al momento de la creación que siempre exige novedad y, en el caso de la danza contemporánea, ruptura. Dada la clara similitud de esta consigna con el trabajo etnográfico de observación, se propuso a los estudiantes y a las estudiantes que, en grupos, alguien guiara una pequeña danza, dos o tres bailaran y dos tomaran notas de lo observado. Se entregó al guía de cada grupo la transcripción de las palabras de Paxton -algunos de estos fragmentos se transcriben a continuación-y se les indicó que debían introducir a sus compañeros y compañeras en la danza, pero que podían utilizar el texto de la manera que desease (leerlo previamente, leerlo mientras se danzaba, darlo a leer a los compañeros y compañeras, parafrasearlo, mostrarlo con su cuerpo, guiar a sus compañeros y compañeras mediante el tacto, etc.).

Extractos del guion de La pequeña danza entregado a los grupos:

El texto debe ser recitado lentamente, con pausas entre cada frase.

La pequeña danza, el soporte

Relájate profundamente en el cono de la cavidad ocular. Imagina una línea que corre entre las orejas. Ahí es donde descansa el cráneo. Haz el movimiento, muy pequeño, para "Sí". Esto hace que el cráneo se balancee en la vértebra superior, el atlas. Tienes que intuir los huesos. Como una rosquilla. La sensación que lo rodea lo define. Haz el movimiento para "No." Entre estos dos movimientos puedes su tamaño pues la longitud a su cargo determinar la longitud de las vértebras.

[...] Inflando los pulmones. Respira desde la parte inferior del pulmón hasta la clavícula. ¿Puedes expandir las costillas hacia fuera y hacia arriba y hacia atrás fácilmente? Definiendo el diafragma en términos de sensación. Parte inferior del pulmón. Dos cúpulas de músculo. Así que con cada respiración estás masajeando los intestinos ... Lo que el diafragma está haciendo es una señal para el resto del cuerpo. Cielo arriba, tierra abajo...

[...] Has estado nadando en la gravedad desde el día que naciste. Cada célula sabe dónde está el abajo. Fácilmente olvidado. Tu masa y la masa de la tierra llamándose uno al otro ...

[...] Fuerza ascendente de los huesos. Los omóplatos caen por la espalda, relajando los intestinos en el cuenco de la pelvis ... En la dirección en la que los brazos están colgando, sin cambiar esa dirección, haz el estiramiento más pequeño que puedas sentir. Puede ser más pequeño. Puedes hacer menos.

[...] Posición vertical ... columna vertebral erguida ... Siente la parte inferior del pulmón, el diafragma, siente que masajea los órganos, abajo hacia el cuenco de la pelvis, relaja tus genitales y ano ... respira profundamente ... exhala lentamente ... 
siente la pausa en la exhalación ... Atento al comienzo de la inhalación ... Esta cosa, el tiempo ... lleno de prisa y pausa ... siente el tiempo pasar a través de la respiración ... no inicies la respiración ... sólo observa ese período ... trata de capturar tu mente, el momento exacto en que la inhalación comienza de nuevo...

De pie ... Relájate erguido con el peso hacia la mitad posterior de la rodilla, pon un poco de peso en el metatarso ... relaja el cuero cabelludo ... relaja los párpados ... relaja detrás de los ojos ... profundamente dentro de las cuenca[s] ocular[es] ... no gastes ninguna energía bloqueando o enfocándote ... deja tus ideas fluir ... porque ciertas cosas enmascaran otras cosas ... y es mejor para esto ahora mismo no tener concentración ... siente el juego del apurarse y de la pausa de la pequeña danza que te sostiene vertical cuando te relajas ... A través de la simple masa y del equilibrio ... $60 \%$ en el metatarso, algo a los dedos de los pies, el resto atrás ... rodillas un poco relajad[as] ... Deja que tu respiración guíe tu torso, haciéndote simétrico ... deja que tus costillas estén abiertas al inflar de los pulmones ... Los brazos caen a los lados ... Siente la pequeña danza ... siempre está ahí

[...] Imagina, pero no lo hagas, imagina que estás a punto de dar un paso adelante con tu pie izquierdo. ¿Cuál es la diferencia? De nuevo a pie ...

Imagínese, pero no lo haga, imagine que está a punto de dar un paso con su pie izquierdo.

¿Cuál es la diferencia? Vuelve al soporte ...

Imagina, pero no lo haga, imagina que está a punto de dar un paso con tu pie derecho

[...] tu pie izquierdo ... derecho ... izquierdo, derecho, izquierdo ... el soporte. (Paxton, 2017)

Para llevar a cabo esta actividad, los grupos de estudiantes se ubicaron en el lugar que les resultaba más cómodo. Todos salieron del salón de clase y se ubicaron en los amplios corredores. Cada uno se comportó de manera diferente, hubo casos en que quien guiaba lo hacía mediante sus propios movimientos corporales, en otros casos el guía leía el texto sin saltarse un punto o coma.

La puesta en común posterior a esta actividad resultó muy interesante. Cada uno expresó, desde el rol que le había tocado, las sensaciones vividas. Hubo quienes, haciendo estos "pequeños" movimientos, entraron en estado de una profunda calma que les resultó muy placentera. Mientras que a otros la pequeña danza les resultó inquietante y les provocó, por ejemplo, deseos de "ir a practicar kick boxing", como comentó una estudiante. En cuanto a la relación entre quienes guiaban y eran guiados, se percibió confianza y entrega, sin que mediaran mayores obstáculos y se pudiera generar un ambiente confortable. Resultó muy interesante poner en diálogo las notas de campo de quienes realizaron la observación con las vivencias relatadas por quienes estaban ejecutando los movimientos. Se notaron similitudes, pero también di- 
ferencias y contrastes que ayudaron a comprender la distancia epistemológica que encarna siempre quien observa una práctica corporal. Otra observación por resaltar es que, en todos los casos, los estudiantes y las estudiantes se sumergieron en la actividad sin notar a la gente que pasaba cerca y se detenía a mirar sorprendida por la actividad. Después del ejercicio, en general todos y todas señalaron que sentían tener una percepción y una sensibilidad modificadas; una especie de mayor conciencia corporal que privilegiaba sentir sus cuerpos sobre el hecho de pensarlos.

\section{Puestas en escena espontáneas}

Luego de presentar algunos enfoques sobre la antropología de la danza y el movimiento, se pidió al grupo de estudiantes que realizara un trabajo de observación de una práctica dancística o un trabajo de descripción de corte autoetnográfico sobre alguna danza o práctica similar que cada uno realizara. A la siguiente clase, cuando se pusieron en común y discutieron algunas de las notas de campo, hubo quienes decidieron realizar sus propias puestas en escena para acompañar esos relatos de campo. Por una parte, se consideró una experiencia muy rica, ya que permitió vivenciar la diversidad de trayectorias vitales presentes en el curso. Por otra parte, desde la perspectiva de los objetivos del curso se dieron algunos aprendizajes o insights que nos interesa señalar.

Mientras una estudiante, docente de Hip Hop bailaba, el resto la seguía en ronda mirándola o acompañando su danza con pequeños movimientos rítmicos. Luego, otra estudiante bailó la danza del vientre, a la cual se dedica de manera artística. Finalizadas estas puestas en escena espontáneas se preguntó al grupo sobre lo que había vivenciado. Espontáneamente, los estudiantes y las estudiantes comenzaron a establecer relaciones entre sus sensaciones corporales como espectadores y conceptos trabajados en clase. Observaron que muchos se desabrigaron mientras sus compañeras bailaban, puesto que habrían sentido calor, y conectaron este fenómeno con la idea trabajada de empatía kinestésica (Sklar, 2000). Los estudiantes y las estudiantes, cuando se miraron unos a otros, también observaron que la gran mayoría mostraba rostros distendidos y sonrientes. Asimismo, algunos puntualizaron cómo el habitual moverse rítmicamente de quienes se encuentran en copresencia de una performance con música, forma parte de un modo somático de atención compartido (Csordas, 2010). Las reflexiones sobre las sensaciones sentidas durante ambas danzas permitieron una mejor comprensión y aprehensión de la propuesta de Csordas, que luego se pudo trasladar al análisis de otras prácticas. 
A través de sus propias danzas, el grupo pudo transformar en aprendizajes significativos algunas ideas ya planteadas teórica y expositivamente que, en abstracto, habían resultado difíciles de aprehender para muchos y muchas estudiantes. Por ejemplo, se resaltó que la kinestesia es considerada un sentido que, a diferencia de los cinco sentidos típicamente reconocidos, su recepción y producción se dan de la misma manera, concretamente en el movimiento mismo (a diferencia, por ejemplo, de las imágenes cuya producción puede ser kinestésica a través del dibujo, pero su recepción es visual) (Sklar, 2000).

Cabe señalar que estas experiencias que consideramos aprendizajes antropológicos fueron viables, ya que previamente existió un nivel de escucha, complicidad y confianza mutua entre los asistentes y las asistentes. Lo cual, como ya fue mencionado, se produjo en torno a nuestra intención de partida de formar un grupo de clase, pero con las características fundamentales de una comunidad de práctica en la que el aprendizaje colaborativo puede darse de manera efectiva.

\section{Resultados}

Poner en juego y jerarquizar lo kinestésico en algunos de los encuentros del curso permitió, sin duda, ampliar la comprensión de textos complejos como la Fenomenología de la percepción. En este sentido, habilitó en cada sujeto la posibilidad de vivenciar experiencias nuevas o repasar sensaciones ya experimentadas, pero volcando su atención hacia estas de una manera nueva, lo cual les permitió cuestionarse observaciones previas. Así, fue posible ponerlas en relación con lo que vivencian otros sujetos cuando realizamos trabajo de campo antropológico. Asimismo, estas experiencias perceptivas, corporales y kinestésicas más holísticas, permitieron o coadyuvaron a generar una cierta forma de producir saber y circular conocimientos en el grupo. Una estudiante lo expresaba de la siguiente manera: "la experiencia produjo en nosotros una especie de communitas que se vio claramente en el cierre, en las ganas de seguir en contacto" (registro de una experiencia de taller, 26 de junio de 2019).

La idea de la communitas es interesante, puesto que refleja el eje temático transversal del curso que problematizaba la noción occidental de persona y, a través de las clases, la fue poniendo en diálogo con las corporalidades otras que se iban trabajando. Especialmente, se problematizó este concepto en el módulo de fenomenología cultural abordado para este artículo, en el que nos interesaba que el grupo integrara la noción ser-en-el-mundo de Merleau-Ponty. También se retomaron las palabras de Silvia Citro (2009) en relación con el hecho de poder hacerlo a través de "la experiencia de la percepción, donde sujeto y objeto constituyen potencias en una relación de complicación" (p. 50). 
Las actividades que propusieron para que el grupo se involucrara en diversas prácticas corporales, permitieron que los estudiantes y las estudiantes comprendieran más cabalmente la noción de reflexividad corporalizada (Rodríguez, 2009). Esta noción se pudo aplicar tanto al baile típico uruguayo del candombe - que la mayoría baila de una u otra manera - como a otros tipos de danza-rituales, como la capoeira. Del mismo modo, al trabajar sobre el ritual-teatro-danza del Nego Fugido que tiene lugar en Acupe (estado de Bahia, Brasil) se pudo identificar una memoria danzada que pasa por ciertos movimientos corporales, que se trata de algún modo de una especie de relato coreografiado, de una memoria que no necesita de un discurso para ser transmitida de generación en generación. Fue gracias a este fenómeno que se pudo discutir la diferencia entre representación y performatividad; entre hacer como si y vivir o experienciar.

Con respecto al objetivo de abordar el estudio de las corporalidades desde una praxis no estrictamente cartesiana y dicotómica, que permitiera que otros saberes como los abordajes fenomenológicos o no occidentales pudieran ser comprendidos, entendemos que la experiencia también fue fructífera. También resultó interesante el módulo dedicado al caso del budismo zen en Uruguay, que incluyó también prácticas corporales ${ }^{5}$. Esto se debe a que en él existe una diferencia entre cuerpo y mente que no se corresponde valorativamente con la distinción cartesiana, y menos aún con la herencia cristiana.

En la segunda prueba parcial realizada al final del curso, el grupo logró generar síntesis interesantes, integrar correctamente las perspectivas teóricas trabajadas y poner en diálogo diferentes autores. En cuanto a la percepción o vivencia del curso, el grupo expresó haber integrado teoría y práctica, así como saber conceptual y experiencial de una manera nueva. Algunos de los comentarios que registramos son muy informales, pero evidencian estas sensaciones de manera clara, por ejemplo: "te parte la cabeza y el cuerpo en mil pedazos", "todo lo aprendido y vivenciado" o "te hacen ser parte y te interpelan de verdad" (registro de una experiencia de taller, 24 de junio de 2019). Si bien, como nos suele suceder al momento de poner en palabras y pasar nuestras sensaciones por el tamiz de lo verbal, a los estudiantes se les hace difícil desprenderse de la inconmensurable herencia cultural dual. Encontramos muy interesante el sustrato de sus apreciaciones que muestran cómo el grupo se sintió convocado e interpelado en sus corporalidades y afecciones.

En este caso, agradecemos al antropólogo Eduardo Gómez Haedo quien compartió generosamente sus trabajos teóricos y prácticos al respecto. 


\section{Conclusiones}

Aunque este curso se trataba de una asignatura dirigida exclusivamente a estudiantes de ciencias antropológicas, por la propuesta temática, había estudiantes con otros bagajes disciplinares previos vinculados a la medicina, las danzas de lo más diversos géneros -desde Flamenco hasta Hip Hop-; la música; la arquitectura y el diseño; el yoga y el taichí; y el trabajo en centros de privación de libertad. Si bien la variedad de esta riqueza era innegable, produjo en momentos iniciales algunos roces, por ejemplo, el cuestionamiento a poner en igualdad relativa las medicinas no occidentales y la biomedicina o la confrontación de diferentes posiciones sobre una supuesta integración cuerpo-mente que sería propia de algunas disciplinas orientales (según cierta doxa). Sin embargo, con el correr de los encuentros el grupo se fue consolidando como tal al ir concibiéndose a sí mismo como una comunidad de práctica. Quienes guiábamos fuimos monitoreando los intercambios y planteando las diferentes propuestas híbridas organizadas de manera gradual en cuanto al involucramiento corporal y sensorial que requerían. Finalmente, las que en un principio parecían diferencias insalvables, se transformaron en experiencias compartidas y fuentes de conocimiento construido en comunidad a través de la implementación de estas consignas performáticas.

Nos interesa destacar la importancia de poner en juego los cuerpos como estrategia didáctica, ya que cuando proponemos actividades que requieren de corporalidades extracotidianas (Barba, 1994), el foco de nuestra atención es impulsado hacia lugares nuevos. Y específicamente en referencia al métier antropológico, nos interesa destacar cómo estas consignas hacen emerger observaciones/percepciones del tipo de las que cualquier profesional puede experimentar en su habitual trabajo de campo, pero que han sido sistemáticamente desplazadas de las genealogías epistemológicas y disciplinares, como lo que sucede con mi temperatura corporal y mis sensaciones en general cuando me aproximo a una u otra persona, o cuando veo a alguien bailar (ejemplo que se materializó claramente en clase). Cuando la atención se vuelca hacia esa información de manera fenomenológica, no solo se amplía el saber antropológico, sino que quienes estén participando pasan a encontrarse en un plano de mayor igualdad. El foco de la búsqueda y las interacciones son esas nuevas percepciones, sensaciones y, en definitiva, ese nuevo conocimiento. Al momento de dialogar, compartir y poner las experiencias en relación con las y los autores referentes, los intercambios se vuelven más igualitarios.

La investigación social y la educativa han demostrado extensamente que al interior de las instituciones, dentro de las aulas, más allá del espíritu democrático de gran parte de la legislación de nuestros países, lejos de igualarnos, no hacemos sino reproducir el enclasamiento y otras desigualdades sociales (como 
podría ser el estatus profesional), las jerarquías étnico-raciales (como la práctica de una religión afro), las de género y las generacionales. Específicamente en las clases de nuestra Facultad ha sido estudiado cómo los varones son quienes suelen tomar y hasta monopolizar la palabra en clase (Madfes, 2004). Por el contrario - y debemos admitirlo-, felizmente hacia el final del semestre en el curso Antropología del Cuerpo se pudo observar que las participaciones y diálogos eran valorados, escuchados y contestados por integrantes del grupo de diversas formaciones, edades y orígenes.

Las hibridaciones entre antropología y muchas de las técnicas y propuestas experienciales que se utilizan en danza contemporánea, específicamente en los contextos investigativos y de creación (muchas de ellas derivadas de la expresión corporal, la performance, entre otras), son herramientas muy útiles para la educación corporal de antropólogos y antropólogas, y de quienes se adentran en el estudio etnográfico de las prácticas corporales. Se trata en general de propuestas accesibles a corporalidades diversas: a cuerpos con diferentes historias, habilidades y sensibilidades adquiridas. Y de ser adaptadas a objetivos pedagógicos, parafraseando a Dewey (1938), son capaces de acortar el camino hacia la percepción de subsiguientes experiencias sin formatear los cuerpos en general ni la percepción en particular (Foucault, 1976), tal como ocurre en la manera altamente normalizadora que ha propuesto siempre la institución educativa tradicional, desde la educación de la primera infancia hasta la universitaria.

\section{Agradecimientos}

El presente trabajo pone en diálogo el aprendizaje acumulado en el Programa Género, Cuerpo y Sexualidad (GCS) de la Facultad de Humanidades y Ciencias de la Educación de la Universidad de la República (Uruguay), que lleva quince años de trabajo en el área de la corporalidad con diversos trabajos de investigación, enseñanza, extensión y publicaciones. También surge de lo que se halló en ediciones previas del curso de grado Antropología del Cuerpo y el trabajo de campo realizado para una tesina en Antropología Social, cuyo registro etnográfico se centró en un año de asistencia a una escuela de danza contemporánea en 2015, pero cuyas observaciones e indagaciones teóricas comienzan unos seis años antes.

\section{Referencias}

Svendler, C., Anttila, E., Rowe, N. y Pernille, T. (2012, 14-20 de julio). The entire school dances: Dance, democracy, and embodiment in a school context [ponencia]. Dance, young people and change: Proceedings of the daCi and WDA Global Dance Summit. Taipei National University of the Arts, Taiwan. https://ausdance.org.au/uploads/content/publications/2012-global-summit/dance-learningrp/young-peoples-embodied-voices-experiences-and-learning-in-dance-education-practices.pdf 
Bardet, M. (2012). Pensar con mover. Un encuentro entre danza y filosofía. Cactus.

Barba, E. (1994). La Canoa de Papel. Tratado de Antropología Teatral. Catálogos.

Citro, S. (2009). Variaciones sobre la corporalidad. En S. Citro (ed.), Cuerpos Significantes. Travesias de una Etnografía Dialéctica (pp 43-82). Biblos.

Csordas, T. (1998). Embodiment as a Paradigm for Anthropology. Ethos, 18(1), 5-47.

Csordas, T. (2010). Modos Somáticos de Atención. En S. Citro (ed.), Cuerpos Plurales. Antropología de y desde los cuerpos (pp. 83-104). Biblos.

Dewey, J. (1938). Experience and Education. Experience and Education. Macmillan.

Foucault, M. (1976). Vigilar y castigar. El nacimiento de la prisión. Siglo XXI.

Freire, P. (1973) Pedagogía del Oprimido. Tierra Nueva.

Gallo, L.E.; Martínez, L.J. (2015) "Líneas pedagógicas para una educación corporal", Cuadernos de pesquisa, 45(157):612-629. https://www.researchgate.net/publication/283565887_Lineas_pedagogicas_para_una_Educacion_Corporal/fulltext/568893b308ae051f9af5c710/Lineas-pedagogicaspara-una-Educacion-Corporal.pdf

Gardner, H. (1983) Estructuras de la mente. La teoría de las inteligencias múltiples. Fondo de Cultura Económica.

Haraway, D. (1985). Ciencia, Cyborgs y Mujeres. La reinvención de la naturaleza. Cultura Libre.

Jackson, M. (2010). Conocimiento del cuerpo. En S. Citro (coord.), Cuerpos plurales. Antropología de y desde los cuerpos (pp. 59-82). Biblos.

Lakoff, G., Johnson, M. (1999). Philosophy in the flesh: The embodied mind and its challenge to western thought. Basic books.

Lave, J. (1991). Situating learning in communities of practice. En L. Resnick, J. Levine y S. Teasley (eds.), Perspectives on Socially Shared Cognition (pp. 63-82). American Psychological Association.

Lave, J. y Wenger, E. (1991). Situated learning. Legitimate peripheral participation. Cambridge University Press.

Lepecki, A. (2006). Agotar la danza. Performance y Política del Movimiento. Universidad de Alcalá de Henares.

Lepecki, A. (2011). Inmóvil: sobre la vibrante microscopía de la danza (R. Rubio, trad.). En D. Taylor y M. Fuentes (eds.), Estudios Avanzados de Performance (pp. 521-548). Fondo de Cultura Económica

Lepkoff, D. (2011). Contact Improvisation: A question. Contact Quarterly 36(1). https://contactquarterly. $\mathrm{com} / \mathrm{cq} /$ article-gallery/index.php\#view =contact-improvisation-a-question

Lorenc, F. (2014). Émile Durkheim y la teoría sociológica de la acción. Andamios, 11(26), 299-322. https://andamios.uacm.edu.mx/index.php/andamios/article/view/206

Madfes, I. (2004). Autonomía y afiliación: el rol de los marcadores conversacionales como índices de género. Ceil/Fhce.

Mauss, M. (1979). Sociología y Antropología. Tecnos.

Merleau-Ponty, M. (1993). Fenomenología de la Percepción. Planeta-De Agostini. 
Mora, A. (2012). El cuerpo en la danza: una etnografía sobre la formación en danzas clásicas, danza contemporánea y expresión corporal. Editorial Académica Española.

Morin, Edgar (2004) Introducción al pensamiento complejo Morín, E. Editorial Gedisa.

Novack, C. (1992). Artifacts (The Empire After Colonialism). Women \& Performance: a journal of feminist theory, 5(2), 82-89.

Panagiotis, K., Ioannou, A. y Retalis,S. (2018). Moving bodies to moving minds: A study of the use of notion- based games in special education, TechTrends 62(6), 594-601. https://doi-org.proxy.timbo. org.uy:88/10.1007/s11528-018-0294-5

Paniagua, A. e Istance, D. (2018). Teachers as designers of learning environments: the importance of innovative pedagogies. OECD Publishing.

Peirano, M. (1995). A favor da etnografìa. Relume-Duma.

Paxton, S. (2017). La pequeña danza, el soporte (M. Blanco, trad.)- Contactimprovisation.blog. https:// escontactimprovisation.wordpress.com/2017/01/26/la-pequena-danza-el-soporte/

Rodríguez, M. (2009). Entre ritual y espectáculo, reflexividad corporizada en el candombe, Avá. Revista de antropología, 14. http://www.ava.unam.edu.ar/images/14/pdf/ava14_m_rodriguez.pdf

Rolnik, S. (2004). Corpo Vibrátil. Arte, Política e Subjetividade. Iluminuras.

Sánchez, G. (2009). La Expresión Corporal-Danza en Patricia Stokoe. En K. Ruano y G. Sánchez (eds.), Expresión Corporal y Educación (pp. 151-174). Wanceulen.

Sklar, D. (2000). Reprise: On Dance Ethnography. Dance Research Journal, 32(1), 70-77. https://doi. org/10.2307/1478278

Tambutti, S. (2009). Inicio de una poshistoria. Steve Paxton y Merelau-Ponty. Los bordes difusos del cuerpo [Seminario Teoría General de la Danza]. Universidad de Buenos Aires, Argentina. https:// nohaymascocoa.files.wordpress.com/2018/07/tee282acc2a0c2a6c3b3rico-me282acc2a0c2a6c3b3dulo-5-uba-2009-21.pdf

Taylor, D. (2011). Introducción. Performance, teoría y práctica. En D. Taylor y M. Fuentes (eds.), Estudios avanzados de performance (pp. 7-30). Fondo de Cultura Económica.

Wacquant, L. (2015). For a Sociology of Flesh and Blood. Qualitative Sociology 38(1), 1-11. https://doi. org/10.1007/s11133-014-9291-y 